\title{
H-ZSM-5 Zeolite Synthesis by Sourcing Silica from the Wheat Husk Ash: Characterization and Application as a Versatile Heterogeneous Catalyst in Organic Transformations including Some Multicomponent Reactions
}

\author{
Isak Rajjak Shaikh, ${ }^{1,2,3}$ Rafique Ahmed Shaikh, ${ }^{4}$ Alamgir Abdulla Shaikh, ${ }^{2}$ \\ Javeed Ahmad War, ${ }^{5}$ Shankar Poshetti Hangirgekar, ${ }^{6}$ Ahmad Lalahmad Shaikh, ${ }^{6}$ \\ Parveen Rajjak Shaikh, ${ }^{7}$ and Rafik Rajjak Shaikh ${ }^{8}$ \\ ${ }^{1}$ Department of Chemistry, Shri Jagdishprasad Jhabarmal Tibrewala University (JJTU), Vidyanagari, Chudela, \\ Jhunjhunu District, Rajasthan 333 001, India \\ ${ }^{2}$ Post Graduate and Research Centre, Department of Chemistry, Poona College of Arts, Science and Commerce, \\ Military Camp Area, Pune, Maharashtra 411 001, India \\ ${ }^{3}$ Razak Institution of Skills, Education and Research (RISER), H.Q.: 1-9-722, Shrinagar, \\ Near Rafaiya Masjid and Hanuman Mandir, Nanded, Maharashtra 431 605, India \\ ${ }^{4}$ Division of Heterogeneous Catalysis, CSIR-National Chemical Laboratory (NCL), Dr. Homi Bhabha Road, \\ Pune, Maharashtra 411 008, India \\ ${ }^{5}$ Department of Chemistry, Dr. Harisingh Gour Central University (DHSGCU), Sagar, Madhya Pradesh, India \\ ${ }^{6}$ School of Chemical Sciences, Swami Ramanand Teerth Marathwada University (SRTMU), Vishnupuri, Nanded, \\ Maharashtra 431 601, India \\ ${ }^{7}$ School of Earth Sciences, Swami Ramanand Teerth Marathwada University (SRTMU), Vishnupuri, Nanded, \\ Maharashtra 431 601, India \\ ${ }^{8}$ Department of Chemistry, Central University of Rajasthan (CURAJ), NH-8, Bandar Sindri, Kishangarh, \\ Ajmer District, Rajasthan 305 801, India
}

Correspondence should be addressed to Isak Rajjak Shaikh; isak@india.com

Received 9 July 2014; Accepted 13 October 2014

Academic Editor: Sankaranarayana Pillai Shylesh

Copyright (C) 2015 Isak Rajjak Shaikh et al. This is an open access article distributed under the Creative Commons Attribution License, which permits unrestricted use, distribution, and reproduction in any medium, provided the original work is properly cited.

ZSM-5 zeolite was synthesized by sourcing silica from wheat husk ash and was converted into its protonated form following careful, conventionally accepted ion-exchange method and calcinations. The H-ZSM-5 zeolite $(\mathrm{Si} / \mathrm{Al}$ ratio $=30)$ prepared was appropriately characterized by XRD, FT-IR, SEM, TEM, TG-DTA, CV, and so forth, and evaluated as recyclable catalyst in selective organic transformations including three- and four-component reactions. The catalytic activity of the zeolite sample supposedly relates to increased density of the accessible acid sites.

\section{Introduction}

Zeolites and related nanoporous materials are widely used as adsorbents, ion-exchangers, and catalysts [1]. In oil and chemical industries, the employment of zeolites as acid cracking catalysts [2] is such that some 350,000 tonnes are used annually for this purpose. Zeolites are a well-defined class of crystalline aluminosilicates [3]. By definition, the zeolite synthesis generally takes place under high $\mathrm{pH}$ conditions and involves crystallization from an inhomogeneous gel of 
a silica source and an alumina source combined with water. Scientific literature and trends in industrial applications established synthetic zeolites as a new commodity.

Today, the growing environmental concerns stemming from the large-scale material syntheses and related industrial activities necessitate the development of "sustainable or environmentally benign" methods. Off late, researchers have recognized that high-value nanoporous materials and zeolites, identical to that prepared using chemical sources, can be synthesized in the presence of organic templates by utilizing lowvalue rice husk ash as a sustainable silica source [4]. Sustainability is a widely used term and encompasses many aspects including careful development and utilization of resources without severely jeopardizing the ecological and environmental health. Biomass and renewable raw materials can be assigned important roles in strategies for sustainable chemistry [5]. Nowadays, for example, the need for generating heat and electricity from renewables is more than ever. Ash production is bound to increase with the increase in the biomass combustion. Neither producers nor end-users know the value of ash. As a result, the ash produced is not treated properly and therefore disposed of. Utilization of biomass ashes has been so far limited to soap production and glass making [6]. In view of the issues with regard to the pollution, there is a need for research on developing innovative products and processes from ash utilization. The ashes are usually categorized into fly ash and bottom ash. Currently biomass (fly) ashes especially from grain polish plant/power stations or fuel pellet combustion [7] are recognized as raw material with soil remediation properties and fertilizers $[8,9]$ due to their constituents such as potassium (as $\mathrm{KCl}$ or $\mathrm{K}_{2} \mathrm{SO}_{4}$ ), magnesium (as $\mathrm{MgO}$ ), or phosphorus (as phosphates). However, in some countries, regulation is in place to prevent environmental and ecotoxicological effects of biomass ash to be used directly on farmland due to its high content of cadmium and other trace elements. Biomass ashes, in particular the bottom ashes, are rich in silica [10] and so recovering value added products or preparing materials from bottom ashes, especially from grain milling plants/grain polish stations, or power stations is desirable. The ashes from rice husk/hulls [4] and Miscanthus grass [11] have shown the potential for forming silicate solutions by alkaline extraction and that can further be used to synthesize high-value materials.

Wheat husk is one of the highest-volume bioresidues worldwide, particularly in India. Open-air burning of wheat husk is still a common practice in Brazil and India causing $\mathrm{CO}_{2}$ emission and related pollution. It was Javed et al. who firstly reported extraction of amorphous silica from the wheat husk [12]. Inspired researchers studied not only the chemical value of extraction residues but also the product distribution and their generation mechanisms through lab-scale combustion and microwave pyrolysis of wheat straw [13]. Terzioglu and Yucel published magnesium silicate synthesized from wheat husk ash [14]. An attractive and potential scalable methodology would be the conversion of the wheat husk based power station bottom ashes into high-purity and useful siliceous ion-exchangers, sorbents, and catalysts. We were the first to report the utilization of silica extracted from the wheat husk ash in synthesizing MCM-41 (Mobil Composite Material number 41) type mesoporous silica [15]. Furthermore, this material was found to have interesting catalytic properties suitable for the Knoevenagel condensation. To the best of our knowledge, the result documented herein is the first synthesis of H-ZSM-5 zeolite by sourcing silica from the wheat husk ash. We once again proved the wheat husk ash as low-cost alternative source to prepare high-cost and highvalue zeolite materials, making it possible to close production life cycles. In addition to that, we also present the applications of this zeolite as a heterogeneous catalyst in various types of organic reactions.

During the course of this research, researchers, namely, Pinar Terzioglu, Sevil Yücel, and Mehmet Öztürk, published a nice short paper [16] entitled "Synthesis and Characterization of ZSM-5 Zeolite from Wheat Hull Ash" on pages 292-296 of The Proceedings of the 1st International Porous and Powder Materials Symposium and Exhibition PPM 2013 (ISBN: 978975-6590-05-8). Our manuscript reports the synthesis of ZSM-5 and H-ZSM-5 zeolite by sourcing silica from the wheat husk ash. Except the source of silica, all the reagents used and stepwise procedure followed during the synthesis of ZSM-5 are similar to those of the previous report [17].

Zeolite Socony Mobil-5 (ZSM-5), first reported [18] by Mobil Co. in 1972, is the end-member of high-silica pentasil zeolite family. It is recognized by the International Zeolite Association of MFI topological category. ZSM-5 is one of the best working heterogeneous catalysts at industrial level due to its varied applications $[3,19,20]$, for example, in gas phase ethylation (the Mobil/Badger process), xylene isomerization, benzene alkylation, hydrodewaxing, methanol to gasoline conversion, and catalytic breakdown of natural oils. It is also found that ZSM-5 can be modified and used for catalyzing some organic transformations under solvent-free conditions [21]. The structure of ZSM-5 zeolite has 10-membered oxygen ring and two types of channel systems with similar size: straight channels $(5.3 \times 5.6 \AA)$ and sinusoidal channels $(5.1 \times 5.5 \AA)$. These two different channels are perpendicular to each other and generate intersections with diameters of $8.9 \AA$. The zeolite has high silicon and low aluminium content that consequently makes its framework hydrophobic in nature. $\mathrm{H}-\mathrm{ZSM}-5$ is the protonic type or $\mathrm{H}$ form of ZSM-5 and has been extensively employed in acid catalyzed industrial chemical processes [22]. It is learnt from the literature that usually the as-synthesized H-ZSM-5 zeolites are known to exhibit low selectivity due to the presence of unselective acid sites located on the external surface and in the pore mouth regions. Therefore, post-synthesis modification mostly described as pore-size engineering [23] is chosen to tailor the properties of zeolites, including the concentration of acid sites. Modification of ZSM-5 to HZSM- 5 can be achieved with a broad range of $\mathrm{Si} / \mathrm{Al}$ ratio (from 6 to infinity). This, in turn, could help zeolite catalysts achieve selectivity by influencing diffusion and overall properties [24]. Transition metal ions can also be substituted into the zeolite framework to arrange active site(s) required for specific reactions [25]. Chemical modification of H-ZSM-5 zeolites by impregnation with acids (e.g., phosphoric/boric acid) led to their catalytic properties in n-hexane cracking [26], 
methanol to hydrocarbon (MTH) conversion [27], toluene disproportionation $[28,29]$, toluene alkylation with methanol [28-30], alkylation of benzene with ethanol [31], and so forth.

We present herein (i) the synthesis of ZSM- 5 by sourcing silica from the wheat husk ash, (ii) the modification of ZSM-5 to $\mathrm{H}-\mathrm{ZSM}-5$ with $\mathrm{Si} / \mathrm{Al}$ ratio of 30 , (iii) the physicochemical characterizations of the sample, and (iv) the catalytic applications. Except the source of silica, all the reagents used and stepwise procedure followed during the synthesis of ZSM-5 are similar to those published by W. Panpa and S. Jinawath (2009) in their research paper titled "Synthesis of ZSM-5 Zeolite and Silicalite from Rice Husk Ash" [17]. Our paper also reports the catalytic behavior of H-ZSM-5 in various types of organic reactions, such as cyclocondensation and some multicomponent reactions (MCRs) that have not so far been proved possible to achieve in a zeolite catalyst such as this. Isak Rajjak Shaikh is the principal investigator of this research and the lead author of this communication. Here, no claim is being made for first publishing ZSM- 5 sourcing silica from wheat waste stream because during the course of this research, Pinar Terzioglu, Sevil Yücel, and Mehmet Öztürk published a short paper entitled "Synthesis and Characterization of ZSM-5 Zeolite from Wheat Hull Ash" on pages 292-296 of The Proceedings of the 1st International Porous and Powder Materials Symposium and Exhibition PPM 2013 (Editors: Sevgi Kilic Ozdemir, Mehmet Polat, and Metin Tanoglu; ISBN: 978-975-6590-05-8). Herein, the protonated form of $Z S M-5$, that is, H-ZSM-5 with various $\mathrm{Si} / \mathrm{Al}$ ratios, was prepared by modifying the ZSM- 5 synthesized by sourcing silica from the wheat husk ash. We report the first synthesis of H-ZSM- 5 by utilizing wheat husk as a source of silica. As far as highlighting the importance of this original research paper is concerned, it should be stressed that little research was carried out to applications of this catalytic system in the area of multicomponent reactions [32,33]. The novel catalytic applications of H-ZSM-5 are interesting because the organic transformations over this neat zeolite sample are achieved without having to introduce isomorphously substituted or extraframework or impregnated metal ions or clusters.

\section{Materials and Methods}

The emphasis of this work was to prepare ZSM-5 zeolite material identical to that prepared by using chemical sources of silicates. Accordingly, silica was sourced by the extraction of wheat husk bottom ash and was further used to prepare the microporous aluminosilicates, ZSM-5, and H-ZSM-5 zeolite materials.

Here, in the first part of this paper, the stepwise synthetic methodology involving the preparation of the ZSM-5 and its modification to the H-ZSM-5 is described.

(a) The wheat husk ash was collected from a grain milling \& power plant and firstly boiled in $1 \mathrm{M}$ hydrochloric acid $(\mathrm{HCl})$ at $363 \mathrm{~K}$. It was then washed with double distilled water. The material was slowly subjected to thermogravimetric decomposition and calcined around $823 \mathrm{~K}$ for minimum 6 hours in muffle furnace.
Then, the silica thus extracted was utilized as the raw materials for the preparation of ZSM-5.

(b) The tetrapropyl ammonium bromide (TPABr) templated synthesis of ZSM-5 was carried out [17] by hydrothermal crystallization of reactants $\mathrm{NaOH}$, $\mathrm{H}_{2} \mathrm{SO}_{4}, \mathrm{HCl}$, n-propyl amine, and aluminum sulfate $\left(\mathrm{Al}_{2}\left(\mathrm{SO}_{4}\right)_{3} \cdot 16 \mathrm{H}_{2} \mathrm{O}\right)$ along with the material extracted from the wheat husk ash as $\mathrm{SiO}_{2}$ source. Firstly, gel comprising silica, extracted from wheat husk ash, and $\mathrm{NaOH}$ were dissolved in double distilled water at $353 \mathrm{~K}$. In another beaker, $\mathrm{TPABr}$ solution was prepared in double distilled water at $323 \mathrm{~K}$ and then added to the silica solution. Few drops of $n$ propyl amine solution were added and the mixture was stirred for 10 minutes. The aqueous solution of the aluminium sulfate was prepared in concentrated $\mathrm{H}_{2} \mathrm{SO}_{4}$ and was poured to the wheat husk ash silica + $\mathrm{NaOH}$ or (in-situ formed) sodium silicate and $\mathrm{TPABr}$ template solution at $\mathrm{pH} 11$. The $\mathrm{pH}$ of the mother liquor was maintained in the range of 11 to 12 . The reactants were then subjected to hydrothermal crystallization in Teflon-lined stainless steel autoclaves for one week at around $423 \mathrm{~K}$. Then, the solid produced was filtered out and washed at least five times with deionized water. The solid was dried overnight at $383 \mathrm{~K}$. Finally, the sample was calcined in dry air at $823 \mathrm{~K}$ for $5 \mathrm{~h}$ in furnace to decompose the organic amine template.

(c) H-ZSM-5 was prepared by ion-exchange of sodium form of ZSM-5 with $\mathrm{NH}_{4} \mathrm{Cl}$. This is how $\mathrm{Na}^{+}$in Na-ZSM-5 was replaced with $\mathrm{NH}_{4}{ }^{+}$by impregnating the solution of $1 \mathrm{~mol} / \mathrm{L} \mathrm{NH}_{4} \mathrm{Cl}$ solution at $363 \mathrm{~K}$ to give $\mathrm{NH}_{4}{ }^{+}$form of ZSM-5. Subsequent calcination of $\mathrm{NH}_{4}{ }^{+}$form of ZSM-5 at $773 \mathrm{~K}$ overnight gave its protonated form, H-ZSM-5.

The H-ZSM-5 is preferred as solid acid catalysts in industries because they are noncorrosive, easy to handle, stable, relatively selective, and recyclable and generate less waste as compared to homogeneous catalysts. Two types of acidic sites are usually present in H-ZSM-5: (i) Brønsted acid sites are related to aluminum located in the zeolite framework; (ii) Lewis acid sites presumably stem from the extraframework aluminum or distorted aluminum in the framework. In order to adjust acidity, Jin et al. [34] reported an environmentally benign, timesaving, and improved dealumination method caused by (utilizing) the self-adsorbed water in H-ZSM-5. When treated at around $400^{\circ} \mathrm{C}$, about $80 \%$ acidic amount was removed from parent $\mathrm{H}-\mathrm{ZSM}-5$ and more Lewis acid sites were generated after treatment at $500^{\circ} \mathrm{C}$. The dealumination method was found to decrease the acidity and weaken acid strength. Similarly, the H-ZSM-5 solid sample which we calcined at $823 \mathrm{~K}$ for $5 \mathrm{~h}$ could influence its acid sites and their density and strength. A discussion on appropriate characterization of the H-ZSM-5 sample especially including the characterization of acid sites of this sample by using infrared (IR) spectroscopy is included in the later part of this paper. 


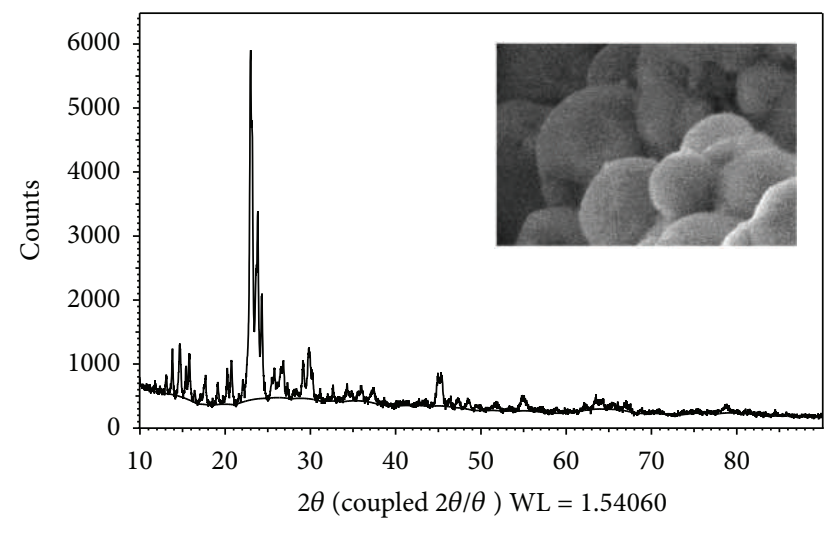

FIgURE 1: XRD pattern of H-ZSM-5 (with SEM image as inset).

\section{Results and Discussion}

3.1. Characterization. In this section of the paper, characterization of the H-ZSM-5 is described. X-ray diffraction (XRD) measurements were performed with a D8 Advance Bruker diffractometer, $40 \mathrm{KV}, 40 \mathrm{~mA}$ current to check if they have the characteristic microporous zeolite structure of the ZSM-5. Transmission Electron Microscopy (TEM) was performed on a Tecnai F20 $200 \mathrm{kV}$ microscope from Philips to confirm the structure and microporous H-ZSM-5. Simultaneous DSC/TGA were recorded using NETZSCH STA 449 F1. DSC and TG analyses were carried out using $10 \mathrm{mg}$ of the sample at a heating rate of $10^{\circ} \mathrm{C} \mathrm{min}^{-1}$ up to $1000^{\circ} \mathrm{C}$, in nitrogen under a flow of $60 \mathrm{~cm}^{3} \mathrm{~min}^{-1}$. Infrared spectra were recorded on a Fourier transform infrared (FT-IR) spectrophotometer (Shimadzu model $8400 \mathrm{~S}$ ) with a resolution of $2 \mathrm{~cm}^{-1}$ and in the range $400-4000 \mathrm{~cm}^{-1}$. Cyclic voltammetry (CV) measurements were done on 7G7 VA Computrace (Swiss model) instrument with glassy carbon electrode as the working electrode, tetramethyl ammonium bromide as a supporting electrolyte, $\mathrm{Ag} / \mathrm{AgCl}$ as the reference electrode, and Pt electrode as counter electrode. DMF was used to dissolve the sample before the actual measurements were made.

A single crystalline phase of the MFI-structure was confirmed by observing the typical reflection peaks at $2 \theta$ of 7.94, 9.07, 13.96, 23.98, 24.57, 26.02, 27.05, 29.22, 29.46, 45.14, $29.42,30.10$, and 45.44 degrees, and so forth (Figure 1). The HZSM-5 zeolite was hydrothermally and chemically stable and the XRD patterns were similar to that of the usual H-ZSM5 reported earlier in the scientific literature [35]. Scanning Electron Microscopy (SEM) deduced the morphology of the zeolite. Figure 1 (SEM image as inset) shows spherical morphology of the structures.

The silicon to aluminium ratio $(\mathrm{Si} / \mathrm{Al}=30)$ was determined by elemental analysis and the atomic absorption spectroscopy (AAS). Elemental analysis of the H-ZSM-5 catalyst used in this study was performed by the electron dispersive spectroscopy (EDS) as shown (Table 1) in weight\% and atomic\%. The spectrum (Figure 2) contains strong characteristic peaks of $\mathrm{Si}, \mathrm{O}, \mathrm{Al}$, and $\mathrm{C}$ as expected, together with additional peak corresponding to $\mathrm{Cu}$. This is either an impurity
TABLE 1: Elemental composition in weight $\%$ and atomic wt $\%$.

\begin{tabular}{lcc}
\hline Element & Weight\% & Atomic\% \\
\hline C K & 7.47 & 12.82 \\
O K & 42.12 & 54.28 \\
$\mathrm{Al} \mathrm{K}$ & 1.64 & 1.25 \\
$\mathrm{Si} \mathrm{K}$ & 38.39 & 28.19 \\
$\mathrm{~S} \mathrm{~K}$ & 0.28 & 0.18 \\
Cu K & 10.11 & 3.28 \\
\hline Total & 100 & 100 \\
\hline
\end{tabular}

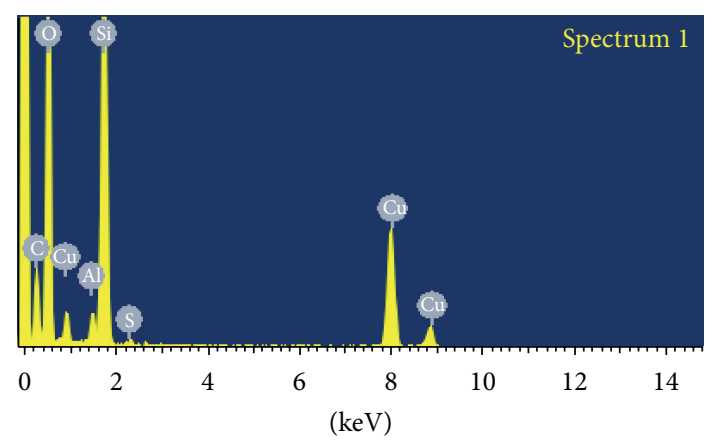

Full scale 1065 cts cursor: -0.170 ( 0 cts $)$

FIGURE 2: EDS.

or artifact arising from the $\mathrm{Cu}$ grid on which the sample is supported.

The examination of defects and phases of zeolite character was made by the TEM (Figure 3). The aggregates observed at couple of places in TEM images need explanation and could correspond to the crystalline aluminium oxide phases or A1 oxidic systems, isolated in some significant stages of the surface dehydration. These aggregates might have been dispersed on the surface and also inside the pores of zeolite by solid-state reactions at calcination temperature via a surface process. During this process, aluminum oxide can react with the silanol and bridging hydroxyl groups and also with extraframework Al species of the zeolite. And also small amount can enter into the pores and react with the bridging hydroxyl groups. Such a modification could partially passivate unselective Brønsted acid sites of the medium pore $\mathrm{H}$ ZSM-5 zeolite framework and might thereby influence their overall catalytic behaviour.

We know that the thermal treatment can cause transformations of one zeolite structure to another, structure collapse to an amorphous phase, recrystallization to non-zeolitic materials, and so forth. Thermogravimetric-diffractometry thermal analysis (TG-DTA) was performed to investigate the mass loss of the zeolite as the temperature increased. TGDTA plot of synthesized H-ZSM-5 (Figure 4) shows that the structure of the zeolite is clearly sustained up to about $723 \mathrm{~K}$ $\left(600^{\circ} \mathrm{C}\right)$. It also revealed distinct mass losses of about $2.63 \%$ ( 40 to $100^{\circ} \mathrm{C}$ ), $3.77 \%\left(100\right.$ to $700^{\circ} \mathrm{C}$ ), and $8.12 \%$ (up to $800^{\circ} \mathrm{C}$; residual mass 92.88$)$.

In principle, the IR spectroscopy could help us understand the active sites and subsequently the mechanisms 

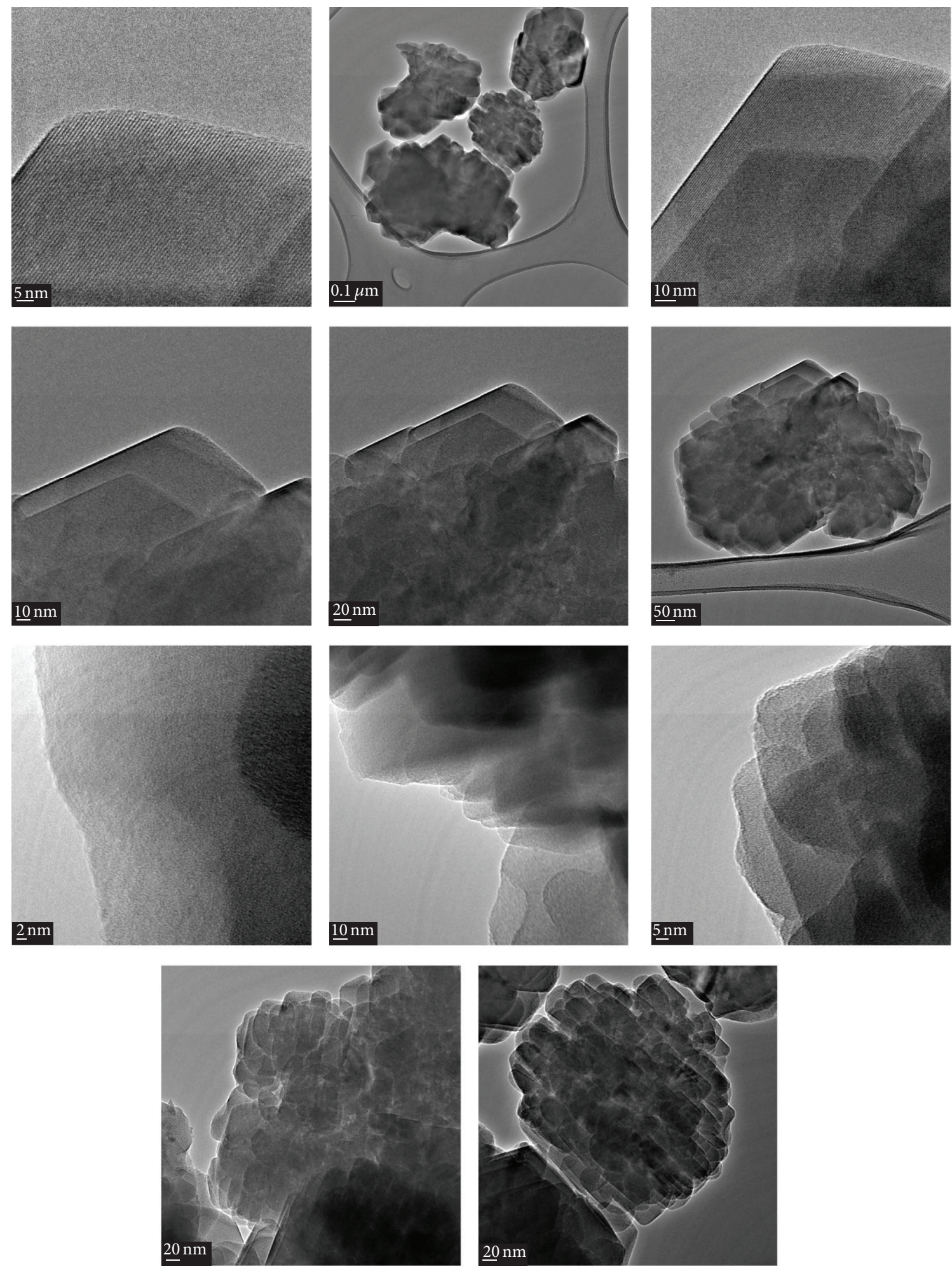

Figure 3: TEM images of H-ZSM-5 obtained from different locations within the sample under study.

invoked in zeolite catalysis. The surface acidity of polycrystalline solids is a complex but technologically important property. In this section, only few preliminary considerations with regard to the acidity of catalytic system and its determination with IR spectroscopy will be introduced. We know that the lattice vibrations characteristic to H-ZSM-5 zeolite usually appear in the range of $400-1200 \mathrm{~cm}^{-1}$, while the bands corresponding to $\mathrm{OH}$ bond vibrations appear at 


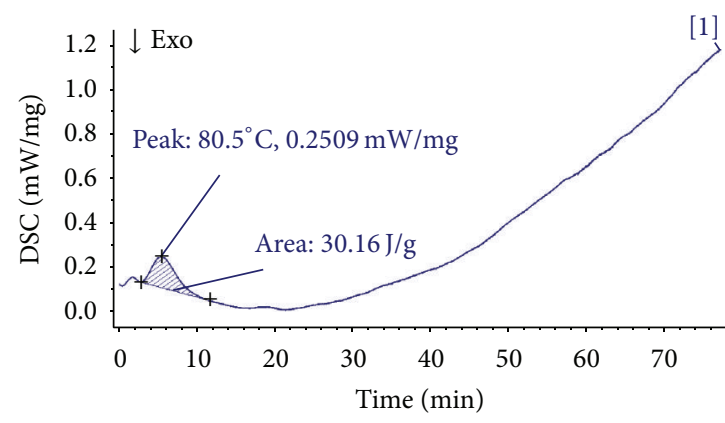

M1.ngb-ds1

M1.ngb-ds

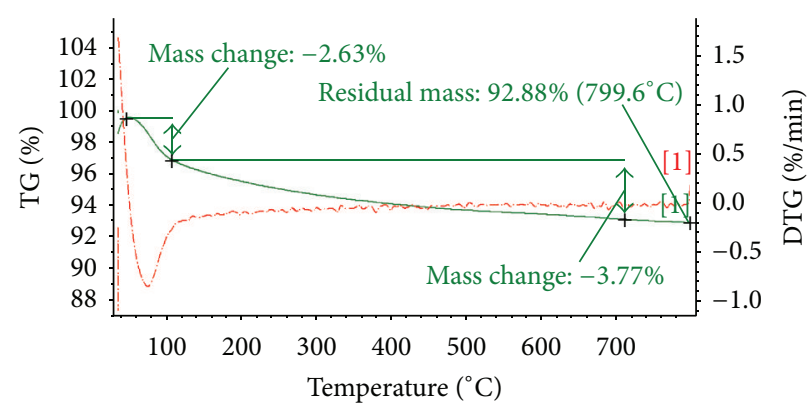

M1.ngb-ds1

— TG

FIGURE 4: TG-DTA curves of H-ZSM-5.

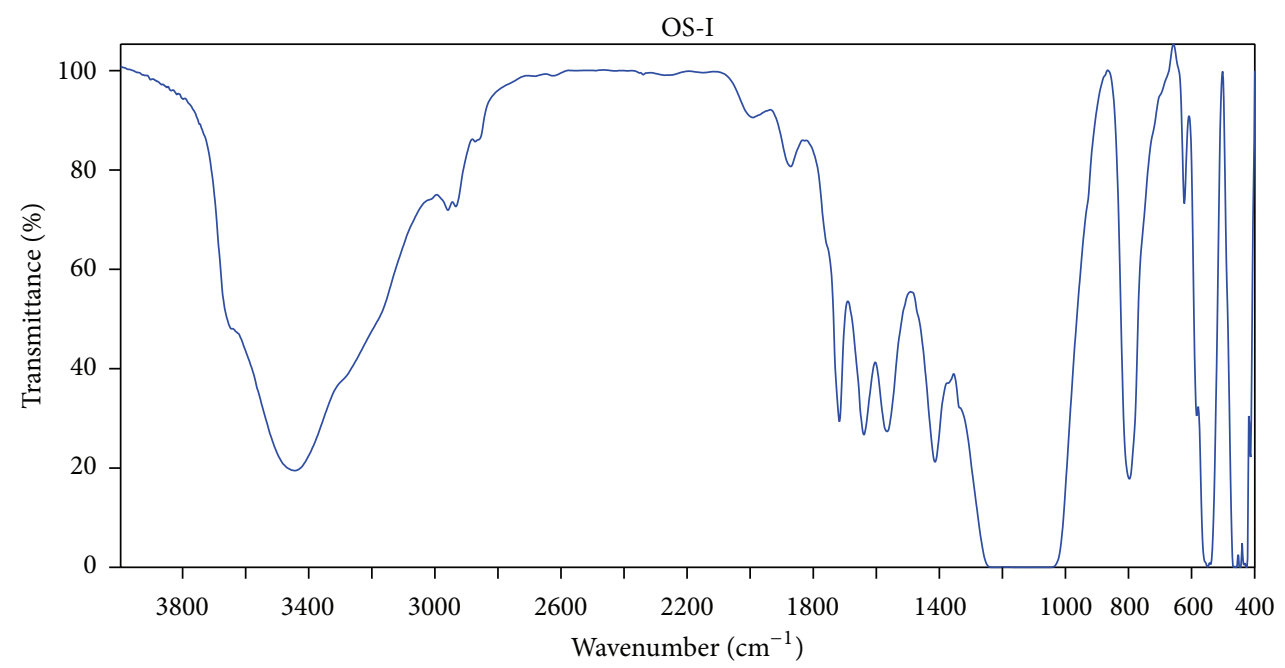

$\begin{array}{cccccc}\text { Wavenumber } & \text { Abs. intensity } & \text { Rel. intensity } & \text { Width } & \text { Found if threshold }< & \text { Shoulder } \\ 3444.2710 & 0.195 & 0.810 & 555.2067 & 76.593475 & 0 \\ 1716.8096 & 0.293 & 0.258 & 25.0512 & 23.024874 & 0 \\ 1639.0132 & 0.267 & 0.356 & 147.3196 & 27.358177 & 0 \\ 1162.2972 & 0.000 & 1.046 & 512.0930 & 95.646698 & 0 \\ 796.9933 & 0.178 & 0.840 & 62.7629 & 78.158562 & 0 \\ 549.3870 & 0.001 & 1.014 & 74.1568 & 94.727798 & 0 \\ 425.1902 & -0.001 & 0.805 & 71.6615 & 74.173943 & 0\end{array}$

FIGURE 5: FT-IR spectrum of H-ZSM-5.

wave numbers higher than $3200 \mathrm{~cm}^{-1}$. Fourier Transform Infra Red (FT-IR) spectrum of the neat H-ZSM-5 zeolite sample, in the range of $400-4000 \mathrm{~cm}^{-1}$, is studied here and shown in Figure 5. The sharp peak at $545 \mathrm{~cm}^{-1}$ and also the bands at $549 \mathrm{~cm}^{-1}, 585 \mathrm{~cm}^{-1}$, and $600 \mathrm{~cm}^{-1}$ could be assigned to the structurally sensitive double five-member ring tetrahedral vibrations, and it is typical for the crystalline ZSM-5 zeolite. The characteristic band of MFI structure corresponding to the bending of the $\mathrm{TO}_{4}(\mathrm{~T}=\mathrm{Si}, \mathrm{Al})$ tetrahedra is found shifted from $450 \mathrm{~cm}^{-1}$ to $425 \mathrm{~cm}^{-1}$ and the IR bands at 780 and $1100 \mathrm{~cm}^{-1}$ can be assigned to the symmetric and asymmetric stretching vibrations of the $\mathrm{Si}-\mathrm{O}-\mathrm{Si}$ linkages of the zeolite framework, respectively [24, 36-38]. The vibration modes of 1046 and $793 \mathrm{~cm}^{-1}$ are assigned to the internal vibration of $\mathrm{SiO}_{4}$ and $\mathrm{AlO}_{4}$ tetrahedra and a small IR band near $1235 \mathrm{~cm}^{-1}$ is attributed to their asymmetric stretching vibration. The $\mathrm{H}-\mathrm{OH}$ bending vibrations of the adsorbed water molecules are observed at $1625 \mathrm{~cm}^{-1}$. The IR spectroscopy carefully observes the acidic hydroxyl $\mathrm{OH}$ groups of solid catalysts [36-38]. Sharp features appearing at $3235,3605,3425$, and $3444 \mathrm{~cm}^{-1}$ correspond to hydroxyl groups of our H-ZSM- 5 whereas in case of the spectrum of a neat $\mathrm{H}-\mathrm{ZSM}-5$, the aforementioned bands usually appear at $3235 \mathrm{~cm}^{-1}$ and $3425 \mathrm{~cm}^{-1}$. The IR band at $3605 \mathrm{~cm}^{-1}$ is 
a characteristic of protonated form of zeolite and its intensity is correlated with framework aluminium (FAL) [39]. Previous works in the literature ascribed the absorption bands at 3745 and $3680 \mathrm{~cm}^{-1}$ to the nonacidic hydroxyl groups and the hydroxyl groups of extraframework aluminum oxide, respectively [36-38]. These IR bands are not observed in our $\mathrm{H}-\mathrm{ZSM}-5$ spectrum. The IR band at $3606 \mathrm{~cm}^{-1}$ corresponds to bridging hydroxyl groups of the Brønsted acid sites that are found responsible for catalyzing cracking [40, 41]. Overall intrinsic activity depends on the local environment [42] and the presence of extraframework aluminium (EFAL) caused by mild steaming is also known to enhance the catalytic activity per $\mathrm{H}^{+}$[43]. Some reports postulated that the extralattice $\mathrm{Al}$ is tetrahedrally coordinated and has at least one $\mathrm{OH}$ group with an IR vibration at $3656 \mathrm{~cm}^{-1}$ while others believed that due to the transformation of tetrahedrally coordinated lattice $\mathrm{Al}^{3+}$ to extraframework $\mathrm{Al}(\mathrm{OH})_{x}$ species, the additional IR band at $3656 \mathrm{~cm}^{-1}$ is seen $[44,45]$. In Figure 5, the IR band around $3660-3690 \mathrm{~cm}^{-1}$ could be attributed to EFAL, bound to the zeolite framework via one or two oxygen bonds, and is consistent with the literature [46]. During the course of this paper preparation, we come across an original research article where the IR band appearing at $3656 \mathrm{~cm}^{-1}$ was assigned to the extraframework aluminium species in proximity of the strongest Brønsted acid site and was found to impact the catalytic activity of ZSM-5 [47]. It is therefore clear that the high specific activity stems from cooperative interaction between Brønsted acid site and an adjacent EFAL. In the IR spectrum of our H-ZSM-5, the band at $3610 \mathrm{~cm}^{-1}$ is attributable to the strongest Brønsted acid sites $\mathrm{Si}(\mathrm{OH}) \mathrm{Al}$ [48]. The IR signal at $3740 \mathrm{~cm}^{-1}$ corresponding to silanol groups $(\mathrm{SiOH})$ in amorphous silica was not seen there. The bands at $3720 \mathrm{~cm}^{-1}$ and $3745 \mathrm{~cm}^{-1}$ related to defect site and terminal silanol group, respectively, are also absent. It can also be said that the $\mathrm{OH}$ group associated with octahedral EFAL is not observed because no IR band appeared around $3780 \mathrm{~cm}^{-1}$ as it was reported in MFI-15 [45].

EFAL is a term that describes chemically different aluminium (Al) species, besides the framework Al. The EFAL could be (i) a charged aluminum oxide, (ii) neutral species such as $\mathrm{AlOOH}$ and $\mathrm{Al}(\mathrm{OH})_{3}$, (iii) aluminum oxo- and hydroxyl clusters, (iv) bulk aluminum oxide aggregates [4951], (v) a partially dealuminated $\mathrm{Al}\left(\mathrm{O}_{3} \mathrm{Si}-\mathrm{O}-\mathrm{Al}-\mathrm{OH}\right)$, and so forth, $[51,52]$. Lewis acid sites are generated due to the presence of EFAL and due to electronic defaults in the framework aluminium (FAL). Marques et al. [53] proposed EFAL as a weaker Lewis acid site than FAL; the IR spectrum of H-ZSM-5 in Figure 5 assigns the band around $1400-1415 \mathrm{~cm}^{-1}$ to Lewis acid sites related to plausible defects. Interestingly, the usual bands at 1444 and $1454 \mathrm{~cm}^{-1}$ corresponding to EFAL and FAL, respectively, are missing. From the preliminary spectroscopic studies, we conclude that the EFAL is identified as the main Lewis acid sites of H-ZSM-5 zeolite sample and is weak. The band at $1400 \mathrm{~cm}^{-1}$ is in agreement with the atomic oxygen linked to strong Lewis acid sites [54]. This unique IR measurement deserves further investigation because this could be the strongest Lewis acid site due to an electronic defect. We were initially tempted to assign the sharp absorption band at

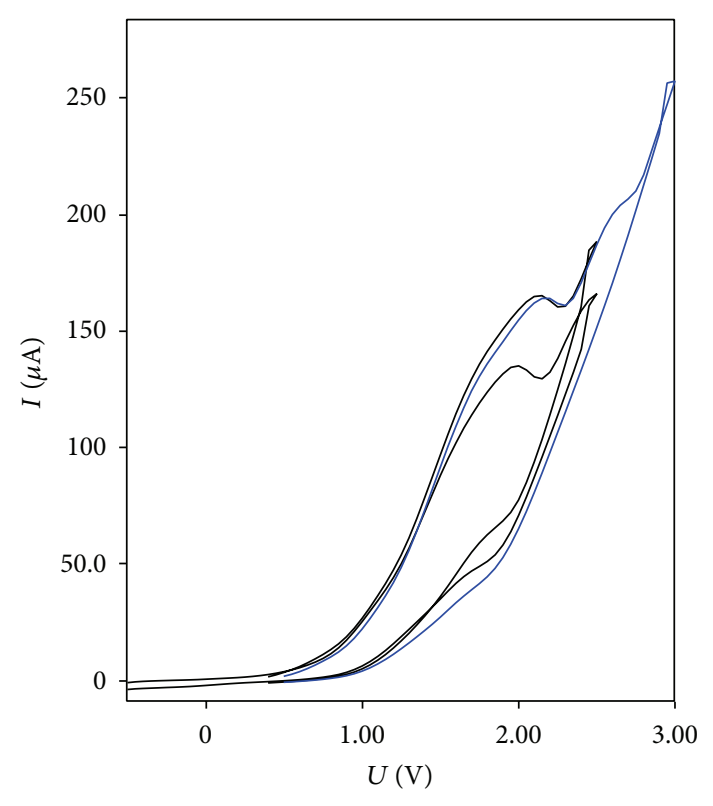

OS1 at different scan rates $v(\mathrm{mV} / \mathrm{s})$

FIGURE 6: Cyclic voltammetry of H-ZSM-5.

$800 \mathrm{~cm}^{-1}$ to the tetrahedral coordination of $\mathrm{Al}$ ions present, as in the transition alumina phase due to stretching vibrations of a lattice of interlinked tetrahedral $\mathrm{Al}$, but there was no peak around $3775 \mathrm{~cm}^{-1}$ which is attributed to the most reactive $\mathrm{OH}$ species on all types of the transition alumina. So, as far as envisaging active sites of H-ZSM-5 is concerned, no one can deny the role of defective crystal configurations, if any. Methodology involving infrared and adsorption of selected probe molecules should be adopted for confirming the surface acidity and the catalytic active sites of this H-ZSM-5 sample [37].

Though the cyclic voltammetry cannot confirm the nature of the redox couple, the peak potential when correlated with standards is an indicator of the possible electroactive and electroinactive species in solid catalyst. The point should also be noted that the synergistic effect of various acid sites might be facilitating a better charge delocalization in the zeolite to result in a more delocalized proton required for a successful protonation of reactant. This is consistent with the result obtained by cyclic voltammetry (Figure 6). An electrode was prepared by incorporation of H-ZSM-5 zeolite in the carbon paste matrix. At this stage, it suffices to say that the cations located inside the pores or extra-framework exhibit electrochemical behavior [55]. This could be due to the mononuclear and or dinuclear oxygenated aluminium species formed on the protonic ZSM-5 surface [56].

3.2. Catalytic Applications. At industrial level, many organic syntheses are catalyzed by conventional strong acids such as $\mathrm{AlCl}_{3}, \mathrm{BF}_{3}$, and $\mathrm{FeCl}_{3}$. Handling hazards, toxicity, difficulty in recovering the catalyst, difficulty in separation of product, and so forth are the problems associated with corrosive acid catalysts under homogeneous conditions and therefore necessitate the development of heterogeneous catalysts. 


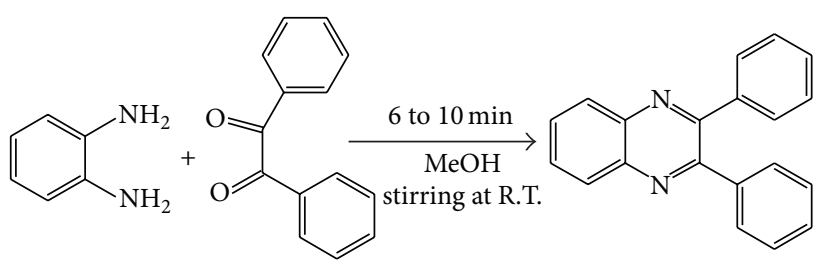

Scheme 1: Classical synthesis of 2,3-diphenyl quinoxaline by cyclocondensation of benzil and benzene-1,2-diamine.

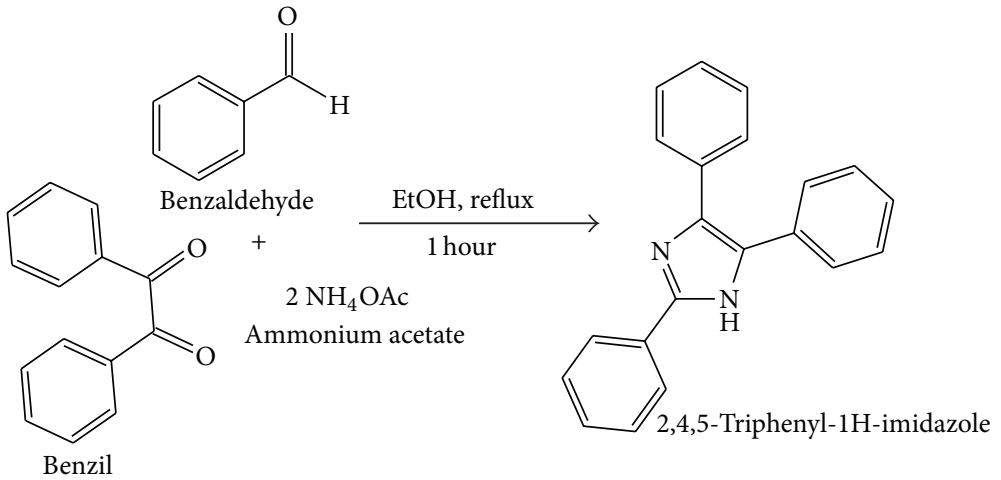

SCHEME 2: MCR for the synthesis of 2,4,5-triphenyl-1H-imidazole.

The zeolites present an environmental advantage over conventional acid catalysts for various synthetic methodologies $[57,58]$. There exist correlations between zeolite properties and catalytic functionality. Catalysts like silica, alumina, and zeolites are known to catalyze condensation, addition, and some other useful methodologies in fine chemicals [58-60]. In the light of the synthetic conditions and the abundant protons present in the high surface area aluminosilicate framework, we investigated how $\mathrm{H}-\mathrm{ZSM}-5(\mathrm{Si} / \mathrm{Al}=30)$ is capable of supporting acid catalyzed reactions. We examined the shapeselective catalysis by carrying out the nitration of toluene with $n$-propyl nitrate as a test reaction. The acidic nature of the catalyst formed nitronium ions from n-propyl nitrate required for nitration reaction. The reaction over this particular catalyst yielded only the para-isomer. This result was in line with the literature [61].

In view of the possible accessibility of acidic sites, we investigated whether $\mathrm{H}-\mathrm{ZSM}-5$ with $\mathrm{Si} / \mathrm{Al}$ ratio 30 is capable of supporting some organic transformations.

Scheme 1. Quinoxalines are a class of nitrogen containing bicyclic heterocyclic compounds and are currently attracting widespread attention due to their wide range of therapeutic applications. Quinoxaline moiety forms the basic skeleton for various antibiotics [62]. The H-ZSM-5 was found to catalyze the classical methodology (Scheme 1) for synthesis of quinoxalines by condensing 1,2-aromatic diamines with 1,2-diketones. The classic synthetic transformation took place at room temperature stirring within 6 to 10 minutes in methanol.

A reaction mixture of 1,2-diaminobenzene $(2 \mathrm{mmol})$, benzil ( $2 \mathrm{mmol})$, and catalytic amount of $\mathrm{H}-\mathrm{ZSM}-5$ was taken in methanol and stirred at room temperature. The reaction was monitored by TLC solvent system: n-hexane/ethyl acetate $(7: 3)$ till its completion. After 10 minutes, the mixture was then poured into ice-water. Solid reaction product was filtered out (yield: $88 \%$ ). The quinoxaline product thus formed was purified by solvent recrystallization using ethanol as solvent. The product thus obtained was confirmed by measuring its melting point $\left(125-127^{\circ} \mathrm{C}\right)$ first. The product of the reaction in Scheme 1 is identified appropriately as 2,3-diphenylquinoxaline (molecular formula: $\mathrm{C}_{20} \mathrm{H}_{14} \mathrm{~N}_{2}$ ).

The product was characterized using ${ }^{1} \mathrm{H}$ NMR (Figure 7) and FT-IR (Figure 8), as ${ }^{1} \mathrm{H} \mathrm{NMR}(\mathrm{CDCl} 3,300 \mathrm{MHz})$ in Figure 7: $\delta 8.18(\mathrm{~m}, 2 \mathrm{H}), 7.78(\mathrm{~m}, 2 \mathrm{H}), 7.48(\mathrm{~m}, 4 \mathrm{H}), 7.34(\mathrm{~m}$, $4 \mathrm{H})$, IR in Figure $8(\mathrm{KBr}) \mathrm{max} / \mathrm{cm}^{-1}: 3057,1602,1442,1346$, $1246,852,767$, and 698 . The described methodology offers advantages of $100 \%$ conversion as well as $100 \%$ selectivity, short reaction time, safe and mild reaction conditions, easy workup, recyclable and efficient catalyst, and so forth.

Despite the tremendous growth in industrial catalysis, the fundamental issues in heterogeneous catalysts with regard to their reactivity, efficiency, and selectivity in catalyzing multicomponent reactions (MCRs) and regioselective syntheses remained unanswered. MCR produces organic compounds in a single step by the breaking and making of several chemical bonds without isolation of any intermediate [63]. This catalyst has found widespread applications in the following MCRs.

Scheme 2. Imidazoles are an important class of nitrogen containing heterocycles. They are attractive compounds for organic chemists due to their useful biological activities [64]. Synthetic methodologies offering green chemistry and 


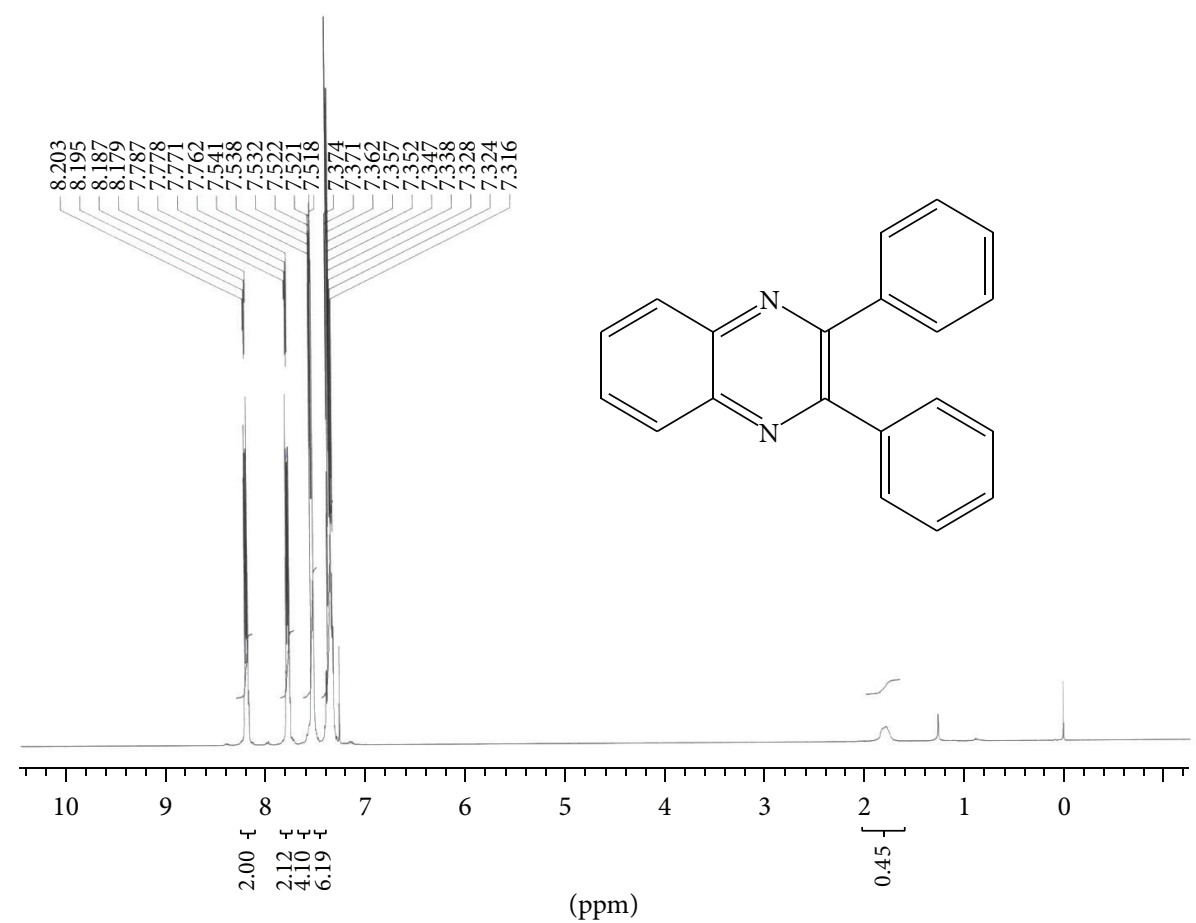

(a)

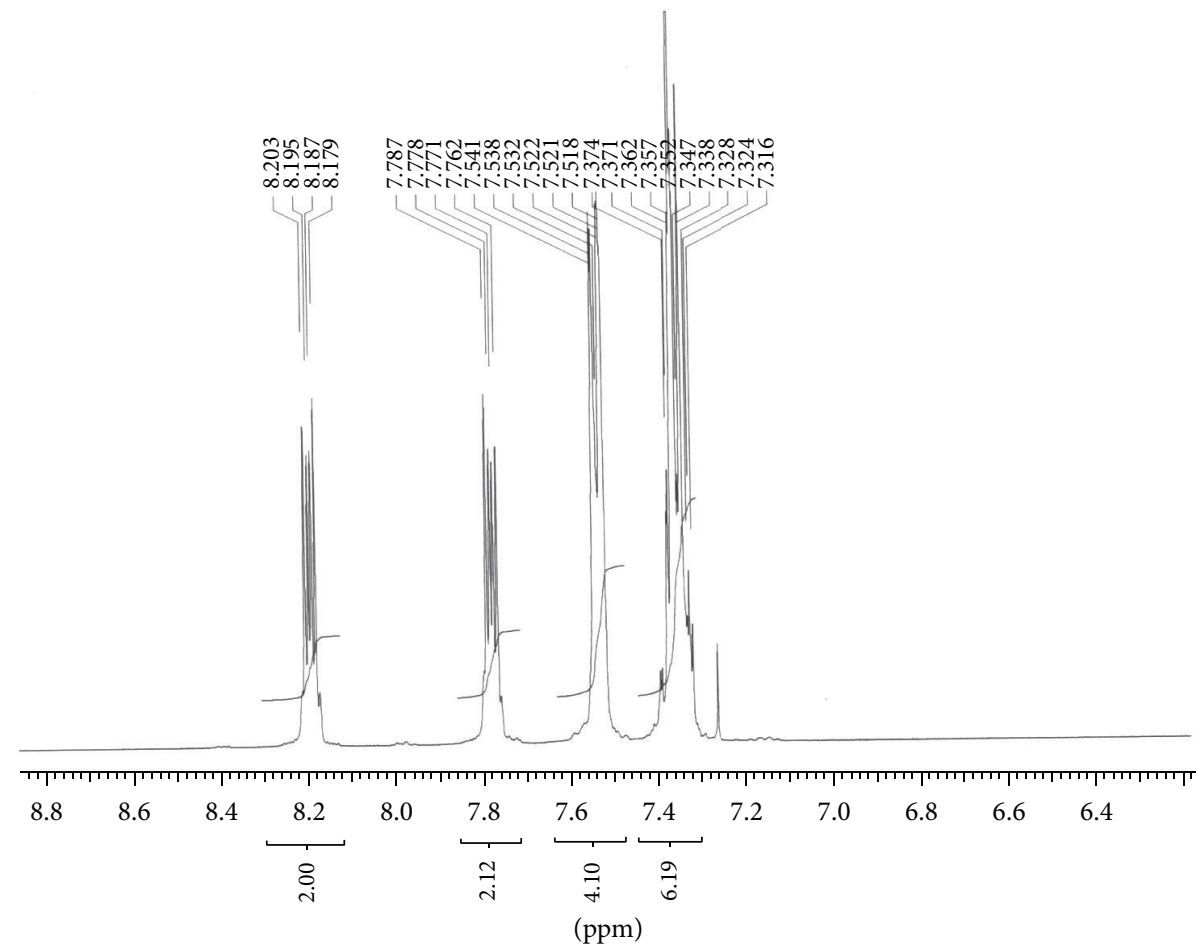

(b)

Figure 7: (a) Normal view and (b) the expanded view of ${ }^{1} \mathrm{H}$ NMR spectrum of 2,3-diphenylquinoxaline.

involving recyclable as well as cost-effective catalyst are in demand [65]. Accordingly, the catalytic methodology demonstrates the synthesis of 2,4,5-triphenyl-1H-imidazole over H-ZSM-5 catalyst by three-component reaction under refluxing ethanol with $100 \%$ conversion within one hour.
Scheme 3. According to the literature reports, organic compounds with pyrimidine and furan as a core unit are known to induce a wide range of biological activities. A three-component Biginelli reaction [66] was carried out over H-ZSM5 (Si/Al ratio 30) catalyst using urea, ethyl acetoacetate, and 


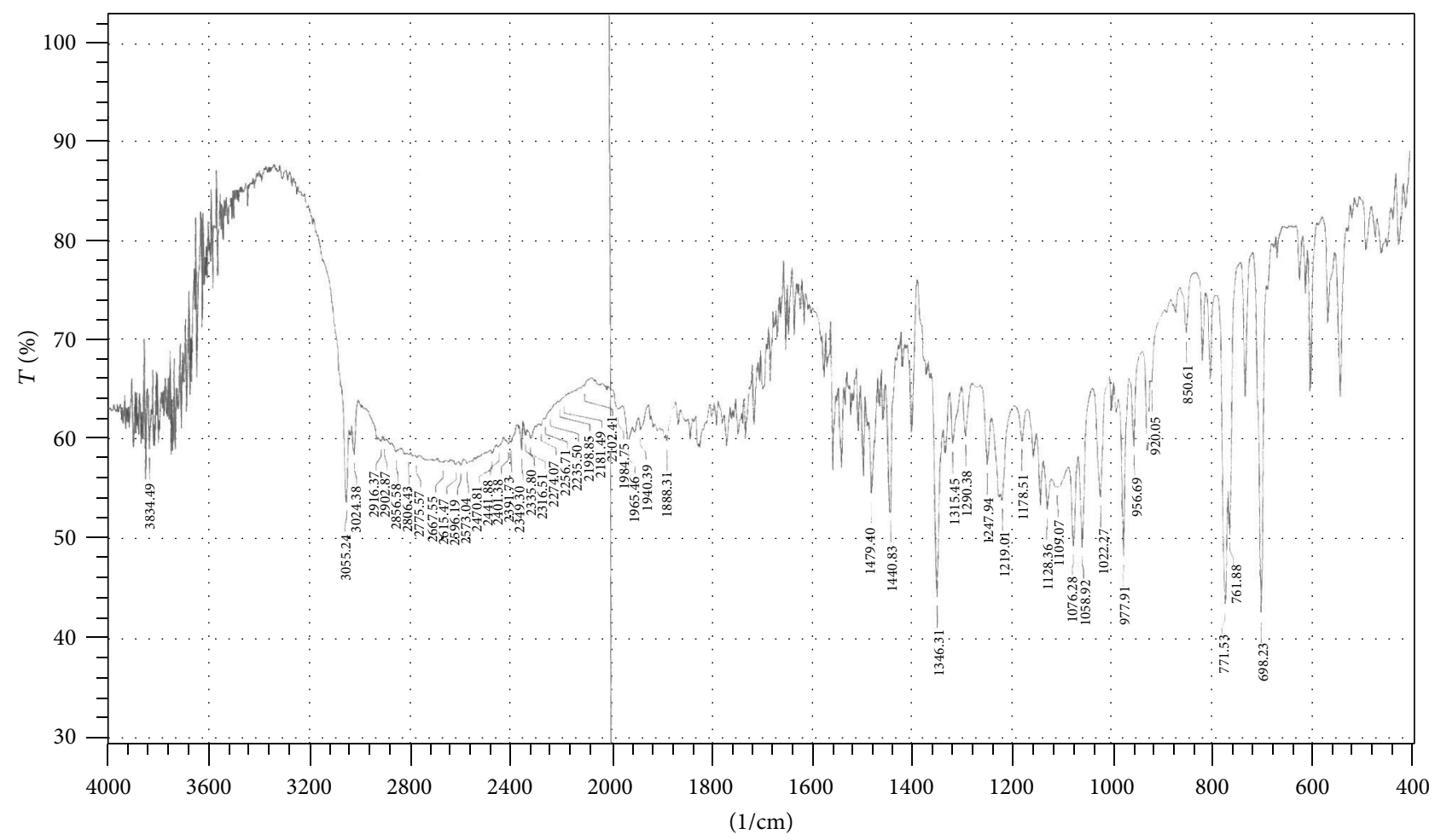

FIGURE 8: FT-IR spectrum of 2,3-diphenylquinoxaline.

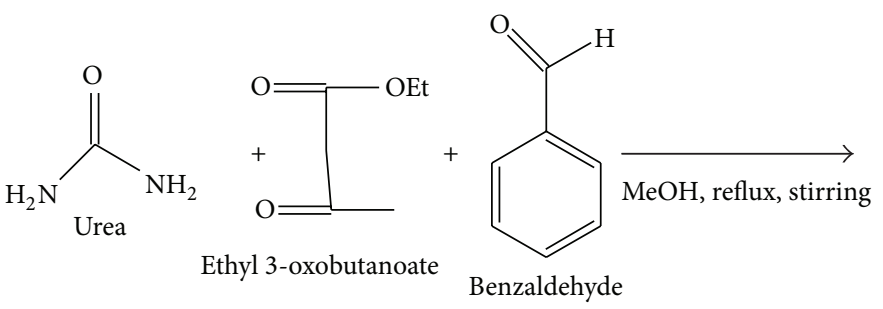<smiles>CCOC(=O)C1=C(C)NC(=O)NC1c1ccccc1</smiles>

Ethyl 1,2,3,4-tetrahydro-6-methyl-2oxo-4-phenyl pyrimidine-5-carboxylate

SCHEme 3: MCR for the synthesis of ethyl 1,2,3,4-tetrahydro-6-methyl-2-oxo-4-phenyl pyrimidine-5-carboxylate.

benzaldehyde as starting materials for one-pot construction of pyrimidin-2(1H)-one derivative as a valuable heterocyclic scaffold.

Scheme 4. An MCR using benzene-1,2-diamine, ethyl 3oxobutanoate, and benzaldehyde as reactants was catalyzed by H-ZSM-5 in methanol at room temperature stirring for about 48 hours to yield ethyl 4-(2-aminophenylamino)-2,5dihydro-5-oxo-2-phenylfuran-3-carboxylate.

The reaction of diamino benzene in methanol took place by addition of diethylacetylene-dicarboxylate and benzaldehyde while stirring at room temperature to yield corresponding ethyl 4-(2-aminophenylamino)-2,5-dihydro-5oxo-2-phenylfuran-3-carboxylate in almost quantitative 55\% yield. These results might generate interest for undertaking unprecedented multi-component organic reactions over this zeolite.
Scheme 5. H-ZSM-5 has demonstrated a simple and greener catalytic protocol for the one-pot four-component reaction, forming a methyl 2-(acetamido(phenyl)methyl)-3oxobutanoate by combining methyl 3-oxobutanoate, benzaldehyde, and acetonitrile and acetyl chloride. The catalyst exhibited the activity which led to $100 \%$ selectivity for the product with a quantitative yield of about $60 \%$. The procedure has the advantages of easy workup and recyclability of the catalyst in this reaction. Furthermore, this synthetic methodology requires inexpensive catalyst, short time, and mild reaction conditions as compared to previously reported methods [67].

Usually, cations generate small volumes of high electrostatic field (active sites) to which a reactant molecule can be adsorbed to cause molecular rearrangements and reactions. The chemical nature, density, strength, and location of the active acid sites in this zeolite could be the important 


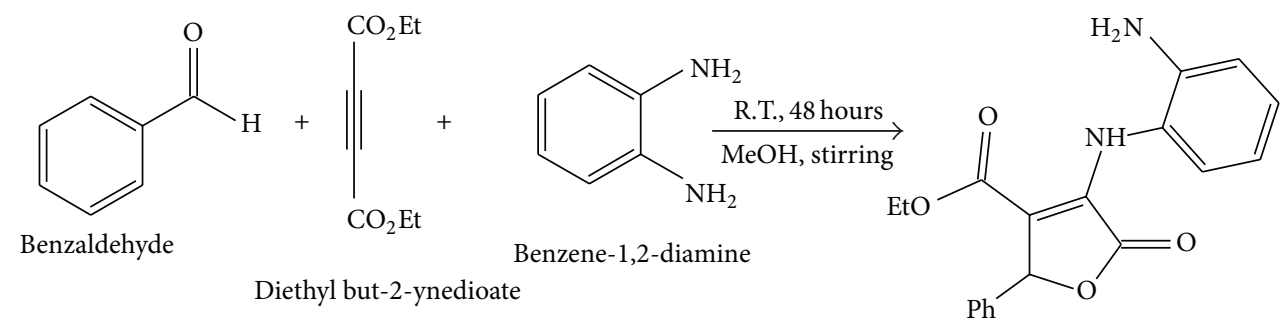

Ethyl 4-(2-aminophenylamino)-2,5dihydro-5-oxo-2-phenylfuran-3carboxylate

Scheme 4: MCR for the synthesis of ethyl 4-(2-aminophenylamino)-2,5-dihydro-5-oxo-2-phenylfuran-3-carboxylate.

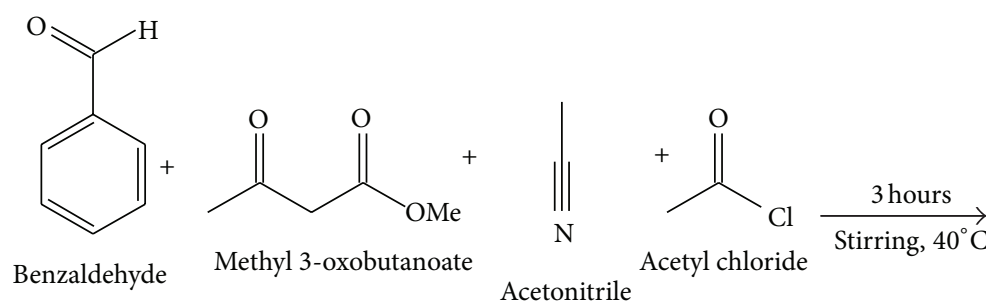

Acetonitrile<smiles>COC(=O)C(C(C)=O)C(NC(C)=O)c1ccccc1</smiles>

Methyl 2-

(acetamido(phenyl)methyl)-3oxobutanoate

SCHEME 5: MCR for the synthesis of methyl 2-(acetamido(phenyl) methyl)-3-oxobutanoate.

parameters which might have affected multicomponent reactions' activities and selectivities. We assume that this catalyst, in principle, possesses high density of well-distributed Brønsted acid sites along with few external Lewis acid sites. Such active sites can exert synergetic effect due to their cooperative interactions. Furthermore, the neighbouring Brønsted acid sites could enhance the catalysis by performing multiple steps in single pot in a sequential manner with high conversion and selectivity. The interaction of heterocycles with H-ZSM-5 zeolite might be taking place via the formation of hydrogen bonded species involving its Brønsted acid sites and the pi-electron system of heterocyclic molecules [68]. There is a saying in the research community of zeolite science that zeolites can be made to catalyse any reaction on the basis of their high surface area alone. For example, the crystal voidage and channels within zeolite provide extensive internal surface to encourage catalytic processes. Most of the zeolite catalysis occurs inside the pores but heterogeneous reactions at the external crystal surfaces can never be ruled out. During the course of this paper preparation, we came across an original research article which reported the influence of the $\mathrm{SiO}_{2} / \mathrm{Al}_{2} \mathrm{O}_{3}$ ratio $(30,80$, and 280$)$ on properties of protonic ZSM-5 zeolite and that paper, in its author's words, showed that the relative weak/strong acidities, as expressed by the ratio of desorption kinetic constants, augment consistently for the H-ZSM-5 studied, with the reduction of the $\mathrm{SiO}_{2} / \mathrm{Al}_{2} \mathrm{O}_{3}$ ratio [22]. In view of the industrial applications of H-ZSM-5, such knowledge [22] could be applied to further our understanding of the H-ZSM-5 zeolite surface and their observations could be taken into account to study mainly the acidic sites and their influence on catalytic properties (stemming from the "Si to Al ratio") of this H-ZSM-5 zeolite material which, here in our case, is prepared by utilizing silica sourced from the wheat husk ash.

A comprehensive account of this research is well beyond the scope of this communication so only the major results are described in brief. It suffices to note that the synthetic approaches for H-ZSM-5 catalytic material using low-cost and relatively environmentally benign silica source of wheat husk ash seem to be not yet published to date. In summary, hydrothermal synthesis of ZSM-5, a microporous aluminosilicate, by sourcing silica from wheat husk ash was followed by its modification to the protonated form. Though such a catalyst might have limited use due to its activity and acid strength declining in the presence of water, it still offers technological advantages such as eco-friendly and efficient organic transformations with catalyst reusability. Isak R. Shaikh and his collaborators reported herein their investigations on accessibility of acidic sites of H-ZSM-5 (with Si/Al ratio 30) for catalyzing some organic transformations including some multicomponent reactions. It is worth taking such a methodology further for preparing relevant aluminosilicates with other functionalities or applications.

\section{Conclusions}

This research paper reported the hydrothermal synthesis of ZSM-5, a microporous aluminosilicate, by sourcing silica 
from wheat husk ash and its further modification to its protonated form (H-ZSM-5) having Si to Al ratio 30. The H-ZSM-5 zeolite sample was appropriately characterized by XRD, SEM, TEM, EDS, FT-IR, TG-DTA, and CV. The zeolite sample of H-ZSM-5 is found to have characteristic crystallinity, good thermal as well as chemical stability, unique catalytic character, and so forth. The synthesis and characterization of $\mathrm{H}-$ ZSM-5 were followed by its evaluation as recyclable catalyst in selective organic transformations including three- and four-component reactions. The efficacy of H-ZSM-5 for these organic reactions suggests the availability of supposedly increased density of the accessible acid (catalytic) sites associated with the MFI-structured zeolite framework Al and or Si atoms. Lessons learnt from scientific literature [34, 37] and, if required, further in-depth investigation of the zeolite structure and the adsorption behaviour will be required before one can explain the activity and selectivity for each and every organic reaction studied. This research demonstrates (i) an attractive and potential scalable and industrially viable methodology for the wheat husk ash based high-purity and useful zeolite H-ZSM-5 synthesis and (ii) the principles of green chemistry such as mild reaction conditions, recyclability of the solid acid catalyst, and selectivity of desired product from organic reactions. On a philosophical note, a methodology based on valorization of a significant agricultural waste stream and also the relevant efforts to diminish the consumer dependency on the chemical reagents (from petroleum or fossil resource) could become important aspects for establishing a sustainable system of catalytic material syntheses for chemical industries in the future.

\section{Conflict of Interests}

The authors declare that there is no conflict of interests.

\section{Acknowledgments}

The financial support of the Razak Institution of Skills, Education and Research (RISER) is gratefully acknowledged. The authors appreciate Dr. Divesh N. Srivastav from the CSIR-CSMCRI for his assistance with XRD, EDS, and TEM facilities. They are grateful to National Metallurgical Laboratory (CSIR-NML) Jamshedpur for AAS analyses. Isak Rajjak Shaikh is the first and corresponding author of this original research paper. This paper is a product of his Ph.D. thesis. He is thankful to the CSIR-NCL (http://www.ncl-india.org/) for providing him with the library facility. The following persons (with their present affiliations to CSIR-NCL, Poona College, DHSGSU, and SRTMU) are on the authors' list because they helped the lead author carrying out some experiments: Dr. Rafique Ahmed Shaikh, Dr. Alamgir Abdulla Shaikh, Mr. Javeed Ahmad War, and Dr. Parveen Rajjak Shaikh. For catalytic applications, he was assisted by collaborators from SRTMU (Dr. Shankar P. Hangirgekar and Mr. Ahmad L. Shaikh) and CURAJ (Dr. Rafik Rajjak Shaikh) with synthetic methodologies over H-ZSM-5 catalyst. Dr. Rafik Rajjak Shaikh did also assist in preliminary observation with regard to the morphology deduced from the first SEM image of the zeolite sample.

\section{References}

[1] C. S. Cundy and P. A. Cox, "The hydrothermal synthesis of zeolites: history and development from the earliest days to the present time," Chemical Reviews, vol. 103, no. 3, pp. 663-701, 2003.

[2] J. Weitkamp, “Zeolites and catalysis," Solid State Ionics, vol. 131, no. 1, pp. 175-188, 2000.

[3] A. Dyer, An Introduction to Zeolite Molecular Sieves, John Wiley \& Sons, New York, NY, USA, 1988.

[4] Z. Ghasemi and H. Younesi, "Preparation and characterization of nanozeolite $\mathrm{NaA}$ from rice husk at room temperature without organic additives," Journal of Nanomaterials, vol. 2011, Article ID 858961, 8 pages, 2011.

[5] J. O. Metzger and M. Eissen, "Concepts on the contribution of chemistry to a sustainable development. Renewable raw materials," Comptes Rendus Chimie, vol. 7, no. 6-7, pp. 569-581, 2004.

[6] M. Verità, A. Renier, and S. Zecchin, "Chemical analyses of ancient glass findings excavated in the Venetian lagoon," Journal of Cultural Heritage, vol. 3, no. 4, pp. 261-271, 2002.

[7] S. Mani, S. Sokhansanj, X. Bi, and A. Turhollow, "Economics of producing fuel pellets from biomass," Applied Engineering in Agriculture, vol. 22, no. 3, pp. 421-426, 2006.

[8] M.-L. Sander and O. Andrén, "Ash from cereal and rape straw used for heat production: liming effect and contents of plant nutrients and heavy metals," Water, Air, and Soil Pollution, vol. 93, no. 1-4, pp. 93-108, 1997.

[9] B. M. Steenari and O. Lindqvist, "High-temperature reactions of straw ash and the anti-sintering additives kaolin and dolomite," Biomass and Bioenergy, vol. 14, no. 1, pp. 67-76, 1998.

[10] A. K. James, R. W. Thring, S. Helle, and H. S. Ghuman, "Ash management review-applications of biomass bottom ash," Energies, vol. 5, no. 10, pp. 3856-3873, 2012.

[11] J. R. Dodson, E. C. Cooper, A. J. Hunt et al., "Alkali silicates and structured mesoporous silicas from biomass power station wastes: the emergence of bio-MCMs," Green Chemistry, vol. 15, no. 5, pp. 1203-1210, 2013.

[12] S. H. Javed, F. H. Shah, and M. Mansha, "Extraction of amorphous silica from wheat husk by $\mathrm{KMnO}_{4}$," Journal of Engineering \& Technology, vol. 18, pp. 39-46, 2011.

[13] X. Zhao, W. Wang, H. Liu, C. Ma, and Z. Song, "Microwave pyrolysis of wheat straw: product distribution and generation mechanism," Bioresource Technology, vol. 158, pp. 278-285, 2014.

[14] P. Terzioglu and S. Yucel, "Synthesis of magnesium silicate from wheat husk ash: effects of parameters on structural and surface properties," BioResources, vol. 7, no. 4, pp. 5435-5447, 2012.

[15] I. R. Shaikh and A. A. Shaikh, "Utilization of wheat husk ash as silica source for the synthesis of MCM-41 type mesoporous silicates: a sustainable approach towards valorization of the agricultural waste stream," Research Journal of Chemical Sciences, vol. 3, no. 11, pp. 66-72, 2013.

[16] P. Terzioğlu, S. Yücel, and M. Öztürk, "Synthesis and characterization of ZSM-5 zeolite from wheat hull ash," in Proceedings of the 1st International Porous and Powder Materials Symposium and Exhibition (PPM '13), S. Kilic Ozdemir, M. Polat, and M. Tanoglu, Eds., pp. 292-296, Çeşme Izmir, Turkey, September 2013. 
[17] W. Panpa and S. Jinawath, "Synthesis of ZSM-5 zeolite and silicalite from rice husk ash," Applied Catalysis B: Environmental, vol. 90, no. 3-4, pp. 389-394, 2009.

[18] R. J. Argauer, M. D. Kensington, G. R. Landolt, and N. J. Audubon, "Crystalline Zeolite ZSM-5 and Method of Preparing the Same," US Patent no. 3702886, Mobil Co., 1972.

[19] J. Weitkamp, "Alkylation of hydrocarbons with zeolite catalysts-commercial applications and mechanistic aspects," Acta Physica et Chemica (Szeged), vol. 31, pp. 271-290, 1985.

[20] F. G. Dwyer, P. J. Lewis, and F. H. Schneider, "Efficient, nonpolluting ethylbenzene process," Chemical Engineering, vol. 83, no. 1, pp. 90-91, 1976.

[21] A. R. Massah, R. J. Kalbasi, M. S. Khalifesoltani, and F. M. Kordesofla, "ZSM-5- $\mathrm{SO}_{3} \mathrm{H}$ : an efficient catalyst for acylation of sulfonamides amines, alcohols, and phenols under solventfree conditions," ISRN Organic Chemistry, vol. 2013, Article ID 951749, 12 pages, 2013.

[22] A. S. Al-Dughaither and H. de Lasa, "HZSM-5 zeolites with different $\mathrm{SiO}_{2} / \mathrm{Al}_{2} \mathrm{O}_{3}$ ratios. Characterization and $\mathrm{NH}_{3}$ desorption kinetics," Industrial \& Engineering Chemistry Research, vol. 53, no. 40, pp. 15303-15316, 2014.

[23] E. F. Vansant, Pore Size Engineering in Zeolite, John Wiley \& Sons, Chichester, UK, 1990.

[24] S. Sengupta, D. Ghosal, J. K. Basu, and P. Kamble, "Chemical modification of HZSM-5 for selective methylation," International Journal of Chemical Reactor Engineering, vol. 10, no. 1, article A22, 2012.

[25] J. C. Vedrine, "Isomorphous substitution in zeolitic frameworks procedures and characterization," in Zeolite Chemistry and Catalysis, vol. 69 of Studies in Surface Science and Catalysis, pp. 25-42, 1991.

[26] H. Vinek, G. Rumplmayr, and J. A. Lercher, "Catalytic properties of postsynthesis phosphorus-modified H-ZSM5 zeolites," Journal of Catalysis, vol. 115, no. 2, pp. 291-300, 1989.

[27] J. C. Vedrine, A. Auroux, P. Dejaifve, V. Ducarme, H. Hoser, and S. Zhou, "Catalytic and physical properties of phosphorusmodified ZSM-5 zeolite," Journal of Catalysis, vol. 73, no. 1, pp. 147-160, 1982.

[28] J. Čejka and B. Wichterlová, "Acid-catalyzed synthesis of monoand dialkyl benzenes over zeolites: active sites, zeolite topology, and reaction mechanisms," Catalysis Reviews, vol. 44, no. 3, pp. 375-421, 2002.

[29] N. Y. Chen, W. W. Kaeding, and F. G. Dwyer, "Para-directed aromatic reactions over shape-selective molecular sieve zeolite catalysts," Journal of the American Chemical Society, vol. 101, no. 22, pp. 6783-6784, 1979.

[30] N. Y. Chen, "Reactions of mixtures of toluene and methanol over ZSM-5," Journal of Catalysis, vol. 114, no. 1, pp. 17-22, 1988.

[31] K. H. Chandawar, S. B. Kulkarni, and P. Ratnasamy, "Alkylation of benzene with ethanol over ZSM5 zeolites," Applied Catalysis, vol. 4, no. 3, pp. 287-295, 1982.

[32] S. R. Mistry, R. S. Joshi, S. K. Sahoo, and K. C. Maheria, "Synthesis of dihydropyrimidinones using large pore zeolites," Catalysis Letters, vol. 141, no. 10, pp. 1541-1547, 2011.

[33] R. Rani, N. Srinivas, M. Radha Kishan, S. J. Kulkarni, and K. V. Raghavan, "Zeolite-catalyzed cyclocondensation reaction for the selective synthesis of 3,4-dihydropyrimidin-2(1H)-ones," Green Chemistry, vol. 3, no. 6, pp. 305-306, 2001.

[34] L. Jin, H. Hu, S. Zhu, and B. Ma, "An improved dealumination method for adjusting acidity of HZSM-5," Catalysis Today, vol. 149, no. 1-2, pp. 207-211, 2010.
[35] M. M. M. Treacy and J. B. Higgins, Eds., Collection of Simulated XRD Powder Patterns for Zeolites, Elsevier, New York, NY, USA, 4th edition, 2001.

[36] J. W. Ward, "Infrared studies of zeolite surfaces and surface reactions," in Zeolite Chemistry and Catalysis, J. A. Rabo, Ed., ACS Monograph no. 171, pp. 118-284, American Chemical Society, Washington, DC, USA, 1976.

[37] J. A. Lercher, C. Grundling, and G. Eder-Mirth, "Infrared studies of the surface acidity of oxides and zeolites using adsorbed probe molecules," Catalysis Today, vol. 27, no. 3-4, pp. 353-376, 1996.

[38] E. M. Flanigen, H. Khatami, and H. A. Szymanski, "Infrared structural studies of zeolite frameworks," in Molecular Sieve Zeolites-I, E. M. Flanigen and L. B. Sand, Eds., Advances in Chemistry Series 101, pp. 201-210, American Chemical Society, Washington, DC, USA, 1971.

[39] P. A. Jacobs and R. Von Ballmoos, "Framework hydroxyl groups of H-ZSM-5 zeolites," The Journal of Physical Chemistry, vol. 86, no. 15, pp. 3050-3052, 1982.

[40] A. Bhan, R. Gounder, J. Macht, and E. Iglesia, "Entropy considerations in monomolecular cracking of alkanes on acidic zeolites," Journal of Catalysis, vol. 253, no. 1, pp. 221-224, 2008.

[41] S. Kotrel, H. Knözinger, and B. C. Gates, "The Haag-Dessau mechanism of protolytic cracking of alkanes," Microporous and Mesoporous Materials, vol. 35-36, pp. 11-20, 2000.

[42] Z. W. Yu, S. H. Li, Q. Wang et al., "Brønsted/Lewis acid synergy in H-ZSM-5 and H-MOR zeolites studied by ${ }^{1} \mathrm{H}$ and ${ }^{27} \mathrm{Al}$ DQMAS solid-state NMR spectroscopy," The Journal of Physical Chemistry C, vol. 115, no. 45, pp. 22320-22327, 2011.

[43] M. Niwa, S. Sota, and N. Katada, "Strong Brønsted acid site in HZSM-5 created by mild steaming," Catalysis Today, vol. 185, no. 1, pp. 17-24, 2012.

[44] M. S. Holm, S. Svelle, F. Joensen et al., "Assessing the acid properties of desilicated ZSM-5 by FTIR using CO and 2,4,6trimethylpyridine (collidine) as molecular probes," Applied Catalysis A: General, vol. 356, no. 1, pp. 23-30, 2009.

[45] L. Sommer, A. Krivokapić, S. Svelle, K. P. Lillerud, M. Stöcker, and U. Olsbye, "Enhanced catalyst performance of zeolite SSZ13 in the methanol to olefin reaction after neutron irradiation," The Journal of Physical Chemistry C, vol. 115, no. 14, pp. 65216530, 2011.

[46] C. Mirodatos and D. Barthomeuf, "Superacid sites in zeolites," Journal of the Chemical Society, Chemical Communications, no. 2, pp. 39-40, 1981.

[47] S. Schallmoser, T. Ikuno, M. F. Wagenhofer et al., "Impact of the local environment of Brønsted acid sites in ZSM-5 on the catalytic activity in n-pentane cracking," Journal of Catalysis, vol. 316, pp. 93-102, 2014.

[48] M. Guisnet, P. Ayrault, C. Coutanceau, M. F. Alvarez, and J. Datka, "Acid properties of dealuminated beta zeolites studied by IR spectroscopy," Journal of the Chemical Society-Faraday Transactions, vol. 93, no. 8, pp. 1661-1665, 1997.

[49] E. A. Pidko, S. M. T. Almutairi, B. Mezari, P. C. M. M. Magusin, and E. J. M. Hensen, "Chemical vapor deposition of trimethylaluminum on dealuminated faujasite zeolite," ACS Catalysis, vol. 3, no. 7, pp. 1504-1517, 2013.

[50] P. Sazama, B. Wichterlova, J. Dedecek et al., "FTIR and 27Al MAS NMR analysis of the effect of framework Al- and Si-defects in micro- and micro-mesoporous H-ZSM-5 on conversion of methanol to hydrocarbons," Microporous and Mesoporous Materials, vol. 143, no. 1, pp. 87-96, 2011. 
[51] J. Datka, S. Marschmeyer, T. Neubauer et al., "Physicochemical and catalytic properties of HZSM-5 zeolites dealuminated by the treatment with steam," Journal of Physical Chemistry, vol. 100, no. 34, pp. 14451-14456, 1996.

[52] J. Kanellopoulos, A. Unger, W. Schwieger, and D. Freude, "Catalytic and multinuclear MAS NMR studies of a thermally treated zeolite ZSM-5," Journal of Catalysis, vol. 237, no. 2, pp. 416-425, 2006.

[53] J. P. Marques, I. Gener, P. Ayrault et al., "Dealumination of HBEA zeolite by steaming and acid leaching: distribution of the various aluminic species and identification of the hydroxyl groups," Comptes Rendus Chimie, vol. 8, no. 3-4, pp. 399-410, 2005.

[54] S. M. T. Almutairi, B. Mezari, G. A. Filonenko et al., "Influence of extraframework aluminum on the brønsted acidity and catalytic reactivity of faujasite zeolite," ChemCatChem, vol. 5, no. 2, pp. 452-466, 2013.

[55] J. S. Krueger and T. E. Mallouk, in Kinetics und Catalysis in Microhererogeneuus System, M. Gritzel and K. Kalyanasundaram, Eds., pp. 461-490, Marcel Dekker, New York, NY, USA, 1991.

[56] E. A. Pidko, E. J. M. Hensen, and R. A. van Santen, "Selforganization of extraframework cations in zeolites," Proceedings of the Royal Society A, vol. 468, no. 2143, pp. 2070-2086, 2012.

[57] A. Corma and H. Garcia, "Lewis acids: from conventional homogeneous to green homogeneous and heterogeneous catalysis," Chemical Reviews, vol. 103, no. 11, pp. 4307-4366, 2003.

[58] R. Ballini, D. Fiorini, M. V. Gil, and A. Palmieri, "Michael addition of $\alpha$-nitro ketones to conjugated enones under solventless conditions using silica," Green Chemistry, vol. 5, no. 4, pp. 475476, 2003.

[59] G. W. Kabalka and R. M. Pagni, "Organic reactions on alumina," Tetrahedron, vol. 53, no. 24, pp. 7999-8065, 1997.

[60] H. Ogawa, T. Chihara, and K. Taya, "Selective monomethyl esterification of dicarboxylic acids by use of monocarboxylate chemisorption on alumina," Journal of the American Chemical Society, vol. 107, no. 5, pp. 1365-1369, 1985.

[61] T. J. Kwok, K. Jayasuriya, R. Damavarapu, and B. W. Brodman, "Application of H-ZSM-5 zeolite for regioselective mononitration of toluene," Journal of Organic Chemistry, vol. 59, no. 17, pp. 4939-4942, 1994.

[62] M. R. Islami and Z. Hassani, "One-pot and efficient protocol for synthesis of quinoxaline derivatives," Arkivoc, vol. 2008, no. 15, pp. 280-287, 2008.

[63] J. Zhu and H. Bienayme, Multi-Component Reactions, John Wiley \& Sons, Weinheim, Germany, 2005.

[64] L. Zhang, X. M. Peng, G. L. V. Damu, R. X. Geng, and C. H. Zhou, "Comprehensive review in current developments of imidazole-based medicinal chemistry," Medicinal Research Reviews, vol. 34, no. 2, pp. 340-437, 2014.

[65] A. A. Marzouk, V. M. Abbasov, A. H. Talybov, and S. K. Mohamed, "Synthesis of 2,4,5-triphenyl imidazole derivatives using diethyl ammonium hydrogen phosphate as green, fast and reusable catalyst," World Journal of Organic Chemistry, vol. 1, no. 1, pp. 6-10, 2013.

[66] S. Narayana Murthy, B. Madhav, A. Vijay Kumar, K. Rama Rao, and Y. V. D. Nageswar, "Facile and efficient synthesis of $3,4,5$-substituted furan-2(5H)-ones by using $\beta$-cyclodextrin as reusable catalyst," Tetrahedron, vol. 65 , no. 27 , pp. 5251-5256, 2009.
[67] D. Bahulayan, S. K. Das, and J. Iqbal, "Montmorillonite K10 clay: an efficient catalyst for the one-pot stereoselective synthesis of $\beta$-acetamido ketones," The Journal of Organic Chemistry, vol. 68, no. 14, pp. 5735-5738, 2003.

[68] G. Spoto, F. Geobaldo, S. Bordiga, C. Lamberti, D. Scarano, and A. Zecchina, "Heterocycles oligomerization in acidic zeolites: a UV-visible and IR study," Topics in Catalysis, vol. 8, no. 3-4, pp. 279-292, 1999. 

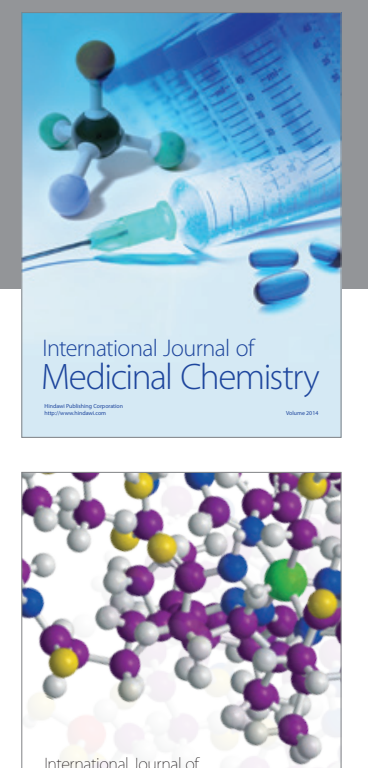

\section{Carbohydrate} Chemistry

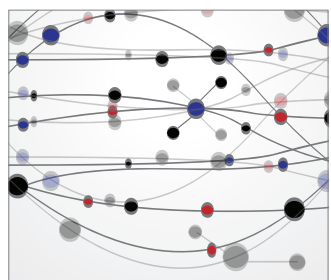

The Scientific World Journal
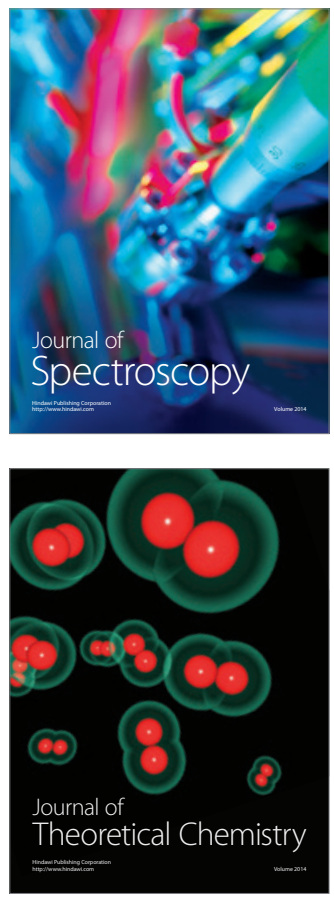
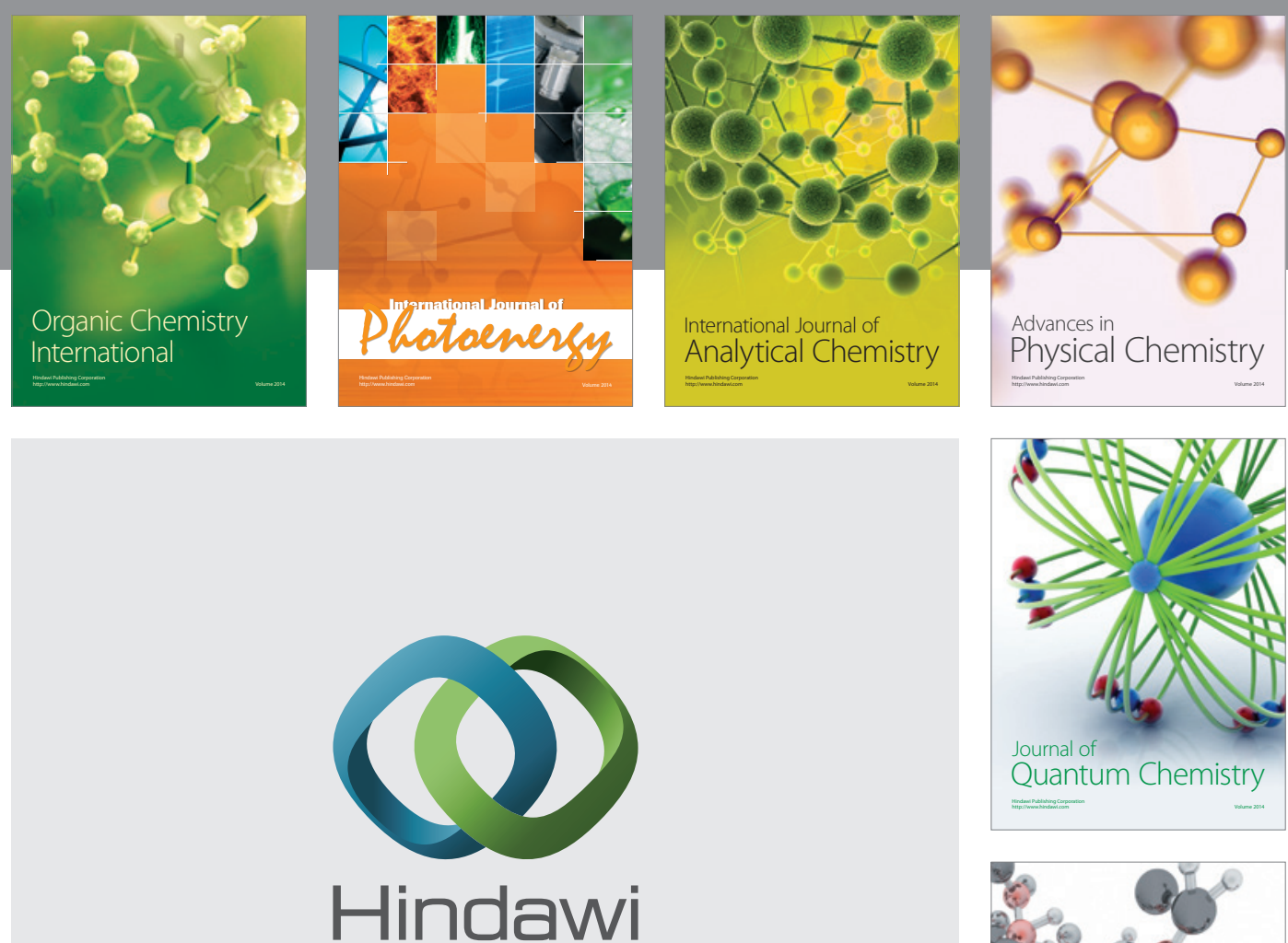

Submit your manuscripts at

http://www.hindawi.com

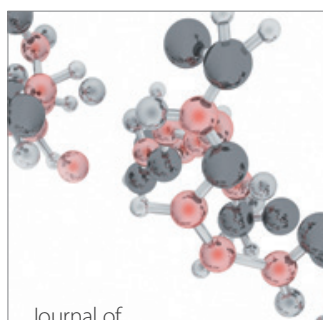

Analytical Methods

in Chemistry

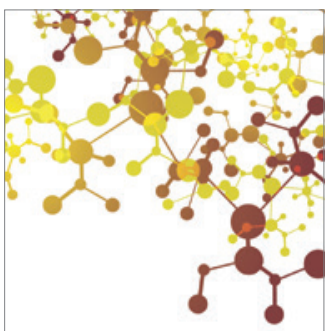

Journal of

Applied Chemistry

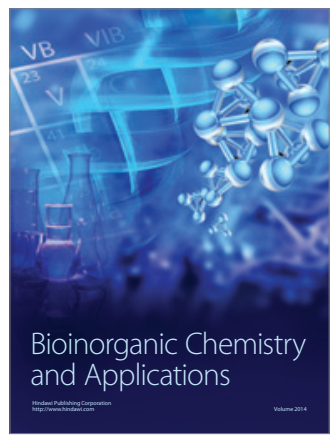

Inorganic Chemistry
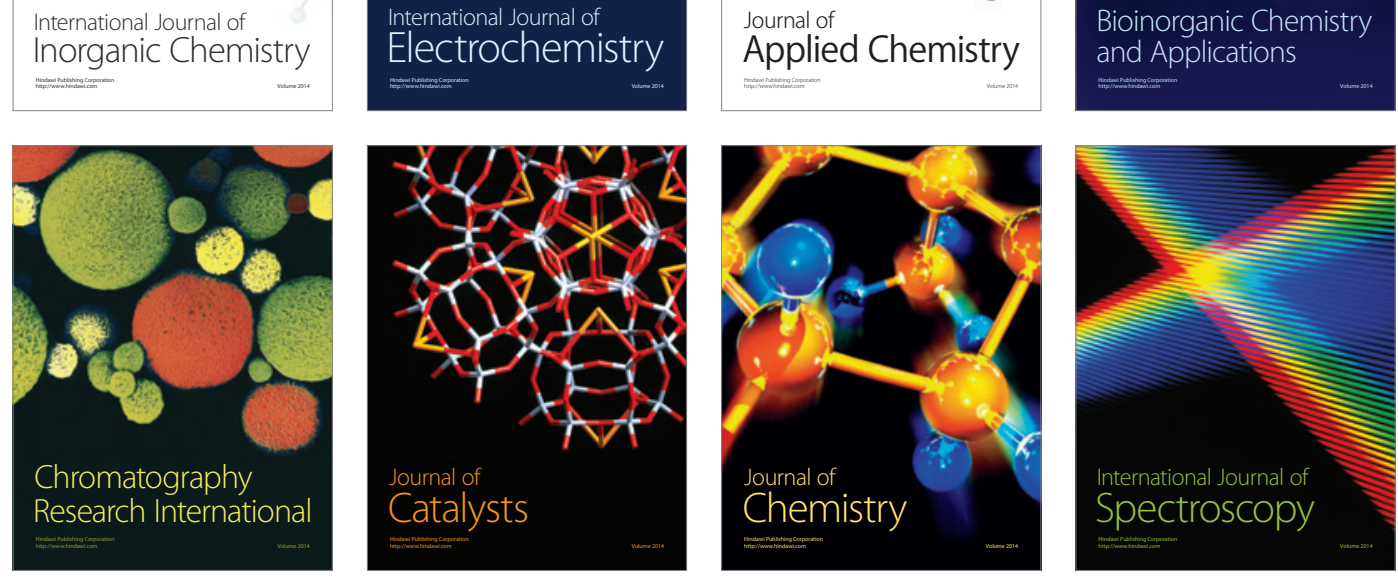